\title{
Outstanding Employees Performance: Personality Traits, Innovation and Knowledge Management
}

\author{
Dr. Eshet Yovav \\ Zefat Academic College, Israel \\ yovave@zefat.ac.il
}

\author{
Prof. Itzhak Harpaz \\ University of Haifa, Israel \\ iharpaz@univ.haifa.ac.il
}

\begin{abstract}
This paper analyzes the relationship among outstanding employees' personality traits, innovation and performance. It stems from Motowidlo, Borman, \& Schmit's theory of performance, which distinguishes between task and contextual performance, leading to personal job success and creativity. The innovative paired sample is composed of both, 189 outstanding employees and their supervisors, and a common employee (182) control group. Findings show that agreeableness and extraversion are significantly correlated to contextual behavior. The present paper contribution is that it enlightens for the first time the relationship the above-mentioned performance. This in turn can be employed as an assessment tool which can assist Human Resources Units in obtaining strategic knowledge of its employees for proactive management of their innovative knowledge assets, for better systematic management of organizational knowledge.
\end{abstract}

\section{Introduction}

Both knowledge and knowledge work processes leading to innovative value-creation have become preeminent in today's knowledge-based economy [1]. Innovative and/or high-skilled knowledge workers are considered indispensable organizational assets [2], thus demanding their proper nurturing and management [1]. Moreover, creativity and the intellectual capabilities leading to the distribution of new ideas have become key to competitive advantage [3], which in itself, is the result of innovation and the persistent ability to manage everincreasing forms of knowledge [4]. Accordingly, organizations' endeavor is to continuously create viable mechanisms combining different forms of knowledge and modes of innovation. Differently expressed, knowledge and innovation are intrinsically associated. Hence, the proactive management of knowledge assets has become crucial for achieving both, innovation capabilities and outstanding performance, which allows companies to maintain leading market positions.

Moreover, companies persistently expect knowledge workers to enhance their knowledge and working skills in their fields of expertise [5]. In addition, knowledge workers are required to cope with different kinds of ambiguities, take multiple risks, intellectually assimilate and apply novel ideas, and respond rapidly to knowledge transformations and updates. In other words, companies expect knowledge workers to become their leading innovators [5]. In this context, ongoing learning allows innovative employees to produce greater novelty, excel in their jobs, improve an organization's creativity, and contribute to its success and growth.

The research literature has acknowledged the importance of promoting innovation by identifying and managing the different channels allowing knowledge circulation. That is the reason recent studies have stressed the importance of hiring knowledge workers, the impact of whom on an organization's competitive power is crucial [6]. More specifically, scholars contend that innovation requires knowledge workers who can maximize the latter's professional potential, successfully fulfill the demands of the labor market [7], open up new roads, and become outstanding performers. Accordingly, enlightening the relationship of outstanding employee's ability to innovatively employ available knowledge and resources has become key in today's management culture.

\subsection{Knowledge Management}

Knowledge management is defined as the organizational process whereby the acts of creating, sharing, using, and managing knowledge and information allows that significant amounts of collected data be methodically processed, organized, and 
converted into professionally useful knowledge [8]. The foregoing allows knowledge workers to significantly improve their company's performance [9]. As thereby, these gain access to the adequate knowledge and information needed for successfully fulfilling their job duties (task and contextual performance), which implies employing and sharing previously established knowledge effectively, and transforming it into innovative entrepreneurial ideas. In this context, scholarly studies have shown that innovation is an outcome of knowledge management, the implementation of which fosters and expands performance's innovative dimension. More specifically, empirical studies have enlightened knowledge management's relation to knowledge creation, acquisition, employment, and innovation. Scholars are certain that innovation leads to value propositions, and thus, to greater organizational performance and competitive edge [9].

Moreover, innovative knowledge workers are employees who create something new for the very first time. Scholars contend that although these employees mostly rely on standard tools and processes to fulfill their duties, they may potentially benefit from further automation [10]. In this context, studies have shown that innovative work behavior is attested when knowledge workers apply creativity and openness to explore new opportunities. Scholars have shown that providing knowledge workers with time and resources to produce usefully innovative solutions is crucial for fostering innovative work behavior (IWB) [11]. In addition, Human Recourses Units may benefit from the metadata and the strategic knowledge they obtain on their employees. Understanding the processes involving the behavior of innovative knowledge workers allows organizations to systematically manage their assets more effectively and improve their innovation policies and outcomes [12].

\subsection{Job Performance and Knowledge Management}

Recent studies on knowledge management have defined the notion of knowledge as the concrete ability to apply this to expand one's potential by taking effective action [13]. Hence, scholars have concluded that not grounding an organization on this is tantamount as to loosing advantage and ground to one's market competitors. In this context, the creation of an organizational knowledge base is key. For knowledge is a precious resource, representing one of the major targets organizations can have. Knowledge management is the discipline that contributes to the achievement of this goal [13]. More specifically, knowledge management practices are connected to controllable organizational aspects. These include tasks associated with supervisory work, knowledge protection, strategic management of knowledge and competence, learning mechanisms, IT practices, and work organization. In addition, knowledge management intersects with other organizational activities such as recruiting, training and development, performance appraisal, and compensation practice, all of which are circumscribed to human resources management practices [14]. Moreover, the notion of knowledge management implies a new way of organizing and sharing intellectual assets, which allows a simultaneous optimization and improvement of productivity and work performance. It implies the management of processes such as the creation, storage, access, and dissemination of an organization's intellectual resources, e.g.: outstanding innovative employees. More specifically, scholars have argued that the notion of knowledge management comprises a set of four different types of processes: (1) the acquisition of knowledge, which includes the processes leading to creation and knowledge-building; (2) the conversion of knowledge, which comprises storage and information retrieval access to useful information ; (3) the application of knowledge, and (4) its protection. In this context, studies have shown that much of the organizational knowledge lies in its employees. Hence, scholars have argued, the knowledgeable involvement of HRM units is crucial for managing the above knowledge and achieving organizational results [15]. Differently expressed, the perspective of knowledge and HRM's management thereof may be seen as complementary insights. Their integration allows organizations to obtain efficient value and generate new creative combinations of existing knowledge. This, in turn, opens the road for new products and/or services-

More concretely, scholarly studies have revealed that intelligent and knowledgeable employees are key organizational resources. Along with creativity, innovation, and the persistent designment of organizational processes and leading technologies, these kind of employees allow businesses to develop leading market positions [16]. In addition, scholars have argued that the relationship between knowledge management and competitiveness' level or business sustainability, implies that knowledge management represents a crucial strategic asset, as it contributes to the increment of performance via employee's interaction and knowledge exchange. It is the increasing identification of knowledge as a strategic organizational asset that has created the need of its methodological management. In short, the organizational processes of knowledge acquisition, development, and application contained in 
the notion of knowledge management are substantial factors determining an organization's levels of competitiveness and survival [13].

The foregoing reveals that knowledge management embodies the creation and sharing of organizational knowledge leading to higher individual performance, and thus to improved organizational creativity [17], both of which enhances entrepreneurship and innovation. This stresses the importance of understanding how outstanding employees fulfil their duties, innovate, and allow higher organizational profit. Now, the research literature discussing the relationship between employee's performance and innovation is rich $[5,18]$. Nonetheless, there is a theoretical gap concerning the relationship comprising outstanding employee's performance, innovation, and personality traits, which this paper closes.

\section{Theoretical Background}

In today's technologically and fast-changing environments, organizations strive to remain competitive, effective, updated, and innovative [19]. Although markets are dynamic and watched, they provide vast businesses opportunities for innovative companies. Innovation is the key to systematic development, and thus, to the marketing of distinguished products and services [20]. Furthermore, innovative performance is an expected work behavior and attitude improving an organizations' outcomes [21]. In this context, innovative work behavior is a process whereby employees' efforts to initiate, introduce and promote new ideas or procedures lead to a positive impact on general work performance, either at an individual, group or organizational level [19, 22]. Moreover, innovative behavior and proactivity play a central role in job performance. Both are desirable skills leading to better task performance and improved network functioning [23]. Differently put, creativity and innovation are critical skills for achieving organizational success [24]. That is the reason competitive organizations are those that understand and internalize the need of optimizing their goals by acquiring knowledge about the interaction of their administrative and performative units.

\subsection{Job Performance and Outstanding Employee's Performance}

The research literature associates performance with the way employees fulfil their duties [25]. The notion of performance represents a multidimensional construct characterizable in several different ways. Nonetheless, scholars usually define it as a function of an employee's work behavioral attitude and its expected outcomes [26].

As to the assessment of an employee's job performance, it can be either determined by employing objective performance data (e.g., sales volume), or through the assessment of an employee's supervisors, peer coworkers, or the employees themselves [27], all of which presupposes the systematic management and employment of organizational knowledge (collective data, information, and body of experience). The foregoing enhances organizational performance [17] via knowledge acquisition and the management of an organizations' employees. It is in this context, that several approaches to performance have been developed over the last fifty years [28]. A recent study has shown that employees' evaluation is fundamental for smooth organizational administration, as thereby organizations may improve their practices and identify different types of performers [29], such as outstanding and common ones.

Our research, stems from [30, 31] job performance model, which evaluates employees' performances by distinguishing between task and contextual performance. Our model presents outstanding performance, innovation and personality as predictors of both task and contextual performance. In addition, it enlightens the theoretical relationship among these as a mechanism which allows organizations to acquire better knowledge about outstanding employee performance and innovation, contributing thereby to a more efficient knowledge management and innovation advantages [14].

\subsubsection{Task Performance}

Task performance refers to an in-role behavior that leads to required outcomes and behaviors, such as specific goods and services produced by an organization in consonance with its goals, which reflect, in addition, the extent to which individuals perform their required job duties [32]. More specifically, task performance comprises two main types of activities: those that directly transform raw materials into goods, and those that facilitate efficient functioning of organizational procedures [33].

\subsubsection{Contextual Performance}

Contextual performance involves extra-role behaviors, like assisting others and/or volunteering [30, 32]. It furthers an organization's effective functioning by supporting, albeit without directly and necessarily influencing its employees' productivity. Contextual performance is highly relevant for team-based work and effective communication within organizations [34], 
which as studies have shown, leads to innovative behavior [35].

More specifically, contextual performance represents those behavioral patterns supporting the psychological and social contexts of action, within which employees perform different task activities [36]. It comprehends those behaviors necessary for performing tasks that surpass the sphere of one's specific job duties. Among other characteristics, contextual performance includes helping and supporting one's colleagues, learning from them, as well as accomplishing tasks for others which are not necessarily included among one's direct responsibilities [37]. Differently expressed, contextual performance is the behavior whereby one puts extra efforts to contribute to one's organization by cooperating and coordinating with one's colleagues [38]. In this context, the multidimensional concept of organizational citizenship behavior (OCB), a synonym of contextual performance, represents the discretionary behaviors exceeding those formal job duties whereby employees try to increase their organizations' functions and effectiveness [39]. More specifically, OCB is subdivided into individually and organizationally oriented behavior (OCBI and OCBO,), both of which are crucial for successful contextual performance.

\subsubsection{Outstanding Performance:}

A major characteristic of outstanding employees is their ability to employ their human capital to effectively improve the general performance of their organization [40]. In this context, exceptional employees find themselves in a superior level. Their performance is the joint result of abilities, personality qualities, and attitudes [41]. Outstanding employees are excellent performers, they surpass their job duties as they situate themselves "above and beyond the call of duty" [42], and show high results as to task and contextual performance, i.e., OCB. Furthermore, identifying and predicting outstanding performance has not only a theoretical, but also a practical importance. Organizations attest this every time they need to fill a key position. In this context, our research provides a unique managment tool. For it introduces a model which helps predict the antecedents of outstanding performers. As recent scholarly work has shown, HRM research has stressed the need to pay more attention when seeking top performing employees, as the beneficial impact these have on an organization's outcomes profit is crucial [43].

\subsection{Personality Traits}

The scholarly popularity of personality traits has grown significantly since the middle of the twentieth century. The Five Factor Model (FFM) has become the most comprehensive scientific tool for consistently measuring personal behavior and psychological characteristics [24]. Scholars have shown that personality factors are key to assessing performance per-se, creative performance, and innovation [44]. Nonetheless, one finds inconsistent results in the scholarly literature as to the correlation of innovative work behavior and personality $[44,45,46]$. The present study settles this problem by introducing an innovative theoretical model that combines the FFM with the categories of innovation and outstanding performance at its two-constitutive levels: task and contextual performance.

The FFM divides personality into five different categories: Agreeableness, Conscientiousness, Openness, Extraversion, and Emotional Stability, all of which are, in turn, composed of additional specific facets. The validity and reliability of the FFM has been widely acknowledged by scholars in different fields [47]. Subsequently, we provide an explanation of the basic components the FFM, along with a preliminary description of their relationship to both innovative behavior and to task and contextual performance, understood as Organizational Citizenship Behavior (OCB), including its individually centered (OCBI) and organizationally focused (OCBO) levels.

2.1.1. Agreeableness: agreeable people are compliant, sympathetic, trusting and cooperative individuals. Highly agreeable persons show adaptive, cooperative and supportively creative behaviors [48]. Furthermore, they are characterized by a high level of altruism and sympathy, as well as by prosocial behaviors and attitudes [49]. Agreeableness is a predictor of task performance [50], and has a significantly positive effect on contextual performance [51]. This notwithstanding, scholars have found that agreeableness does not influence innovative performance [29, 44, 52].

2.1.2. Conscientiousness refers to an individual's degree of self-discipline, dutifulness, deliverability, responsibility, and goal achievement. Highly conscientious employees perceive themselves as wellorganized, hard-working, and careful persons [53]. Conscientiousness is a positive predictor of job performance [54].. Nonetheless, its relation to innovative behavior is inconsistent [45].

2.1.3. Openness to Experience. This trait embodies the pursuit of novelty in new environments, along with the constant search of new experiences [55]. Flexibility, curiosity and imagination are additional characteristics 
thereof. Hence, openness to experience is positively associated with innovative behavior [45]. The research literature has already discussed this trait's importance for predicting performance [51]. Scholars agree on openness to experience's positive performance outcomes. Nonetheless, they disagree as to how this relation is established.

2.1.4. Extraversion refers to a tendency to be sociable, assertive, and energetic. Extroverted employees are likely to take initiatives toward change as well as to effectively present their ideas in an approachable, communicative, and sympathetic manner. Furthermore, extraverted persons tend to welcome challenges and changes [53]. Scholars agree that this trait is a positive predictor of outcomes, including employees' job performances [49, 50, 56], and innovation [57].

2.1.5. Emotional Stability. These are calm, distressed, and placid individuals. They show confidence and optimism in new or challenging situations [58]. Emotional stability is associated to the implementation of knowledge in new tasks, as well as to the ability to adjust to new contexts [59]. Scholars have established that emotional stability is a predictor of task and contextual performance [60,61]. Although the relationship between emotional stability and creativity is ambiguous [62], this trait is associated with view exchanges, thus allowing the promotion of discussions and new ideas [35] comprising innovation processes.

Now, as argued earlier, the scholarly literature reveals [45] that there are theoretical inconsistencies as to the relationship comprising personality and innovation [63], and their impact on task and contextual performance's outcomes. According to one study,[64], agreeableness is the only FFM trait that does not determine innovation significantly. Recent studies have shown, on the other hand, that it does, while conscientiousness does not. [65]. Moreover, scholars have additionally shown that all FFM traits are good and consistent creativity predictors [66]. Among them, openness to experience has been shown to crucially predict creativity and inventive performance [64, 67]. In most studies this conscientiousness it is not positively related to creativity or inventive performance [68, 69], which is extraversion's case, albeit slightly [69]. As to neuroticism and agreeableness, scholars contend that they are creativity unrelated [66].

The present study elucidates the relationship between the FFM and innovation by specially focusing and theorizing on outstanding performance. We accordingly hypothesize:

Hypothesis: Outstanding employees with higher levels of extraversion, openness to experience will show higher contextual performance.

\subsection{Innovation}

In today's competitive global economy, creativity and innovation have become crucial assets allowing organizational effectiveness [20]. Employees exceeding "standard work behaviors" and going beyond mere "formal task requirements" tend to innovate and contribute significantly to organizational success. According to a recent study, the notion of innovative work behavior entails as a process integrating three behavioral elements: (1) the generation, (2) promotion, and (3) implementation of ideas. More specifically, whereas the notion of innovative behavior involves the three foregoing elements, that of creativity refers only to the first, i.e., the process of generating ideas [21]. Thus, innovation is defined as the intentional implementation of new beneficial products, processes, ideas, practices, and procedures, and hence, entrepreneurship [70].

\subsubsection{Innovative Work Behavior}

Innovative behavior involves acts leading to the generation, promotion, and implementation of ideas at any organizational layer. It comprises the detection of new technologies, as well as the suggestion of new ways of achieving goals. Innovative behaviors lead to goal introduction and application, thus contributing to performance improvement at all levels: individual, team, and organizational [62]. In this context, innovatively behaving employees are those who can quickly and appropriately respond to customers, propose new ideas, and create new products, all of which leads to entrepreneurship [70].

Now, empirical researches examining the relationship among innovation, performance, and personality have shown mixed results [62]. Many studies provide evidence of a positive impact of innovative behavior on performance [72]. Employees' innovative behavior is an important organizational asset for both, coping with uncertainty and for succeeding in dynamic business' environments. Accordingly, innovative behavior represents a core source of competitive advantage for dealing with those rapid changes underlying complex productive processes [72].

\subsubsection{Personal Initiative}

Initiative behavior or personal initiative entails as a set of actions accomplished by individuals possessing a self-starting approach to work and showing proactive behaviors [73]. Initiative individuals tend to develop self-set goals, use active planning strategies, and actively explore their environment to create and exploit opportunities. Initiative behavior is also manifested in 
actions such as expending additional energy at work. Recent studies have shown that it predicts job performance [58] In this context, scholars have indicated that job performance is an important outcome of personal initiative [73]. Nonetheless, some hold that personal initiative does not always contribute to higher performance [74]. More specifically, initiative behavior is often connected to the pressure of doing, which may harm effective contributions over time, along with the maintenance of successful performance rates [75]. Innovative behavior is usually measured by using only a single dimension scale [76]. Nevertheless, studies have shown the need to analyze it within a multidimensional construct [45], thus we posit.

Hypothesis: Outstanding Employees with higher levels of openness to experience display higher levels of innovation

Hypothesis 3 : Outstanding Employees with higher levels of extraversion display higher levels of innovation

Hypothesis4: Outstanding Employees with higher

levels of agreeableness display higher levels of innovation

\section{Method}

\subsection{Participants and Procedure}

The sample is composed of a wide variety of elite performers, civil servants, from 14 Israeli Government offices. A total of 742 participants were surveyed, including 189 outstanding and 182 common employees and their supervisors. The questionnaires were completed separately by the employees and their supervisors. The dropout rate among the employees was $38 \%$ and was $55 \%$ among their managers. The sample was selected from the finalists of the 'Worker Prize of Israel' sponsored by Ma'ariv, a daily Israeli newspaper. Each government ministry selected its top-performing employees. Then, a committee consisting of 18 experienced professional members headed by the president of the National Labor Court selected the Outstanding Employees. Cramer's V Correlation shows a medium correlation between outstanding employees and their supervisors' gender, education level, marital status and labor union membership.

\subsection{Instruments}

The instrument was constructed based on an extensive literature review and was adapted to the Israeli context. The paired sample contained employees self- report and supervisor's performance assessment. The employees' questionnaire contained a general information questionnaire, as well as a self-report on personality and innovative behavior. The supervisors' questionnaire contained a performance assessment and innovative behavior evaluation for their personnel.

3.2.1. Personality. Based on Gosling, Rentfrow, \& Swann (2003) developed the Ten-Item Personality Inventory (TIPI), which consists of 10 items assessing the Big Five personality factors. A five-point Likert scale was used for the statements $(1=$ Very Inaccurate through to 5=Very Accurate). The reliability of this questionnaire is acceptable, Cronbach's alpha coefficient of 0.72 .

3.2.2. Innovative Behavior. The innovative behavior of employees is measured twice. The scale, developed by Scott and Bruce (1994), both for supervisors' rate their employees' innovative behaviors, and employees self-report. A five-point Likert scale was used for the statements ( $1=$ strongly disagree through to $5=$ agree strongly). The reliability of this questionnaire is good; Cronbach's alpha for this questionnaire is 0.89 .

3.2.3. Job Performance. We assessed job performance with five items according to task and contextual performance. Supervisors rated job performance, with five-point Likert scales. Task Performance based on Williams and Anderson (1991) have a seven-item scale. The reliability of this instrument is good; Cronbach's alpha coefficient is 0.88. The Contextual Performance scale is based on [79], Cronbach's alpha coefficient of 0.93 [80].

\subsection{Data Analysis}

We analyze the data using Regression analysis and Ttests via SPSS version 25.

\section{Results}

Table 1 represents means and standard deviations of the main study variables. Outstanding employee's Selfreport on innovation was relatively high, $\mathrm{M}=5.53$, which equals to 79 points in a 1-100 scale. It also contains independent sample t-test which shows supervisors report outstanding employees have higher levels of Task Performance, Contextual Performance, but lower levels of Innovation. Outstanding employees self-report higher levels of Personal Initiative, Conscientiousness and Emotional Stability then common employees. 
Table 1: Descriptive Statistics: Ranges, means and standard deviations of main study variables

\begin{tabular}{|c|c|c|c|c|c|c|}
\hline Source & Variable & Employees & Range & Mean & SD & $\mathrm{t}$ \\
\hline \multirow{6}{*}{$\begin{array}{l}\text { Supervisors } \\
\text { Report }\end{array}$} & \multirow[t]{2}{*}{ Task Performance } & Outstanding & $2.86-7.00$ & 6.19 & 0.76 & \multirow{2}{*}{$2.31^{*}$} \\
\hline & & Common & $3.43-7.00$ & 5.96 & 0.45 & \\
\hline & \multirow[t]{2}{*}{ Contextual Performance } & Outstanding & $1.00-7.00$ & 5.89 & 0.83 & \multirow{2}{*}{$2.69^{* *}$} \\
\hline & & Common & $3.57-7.00$ & 5.60 & 0.80 & \\
\hline & \multirow[t]{2}{*}{ Innovation } & Outstanding & $1.83-7.00$ & 5.15 & 1.38 & \multirow{2}{*}{$-3.33^{* *}$} \\
\hline & & Common & $3.33-7.00$ & 5.65 & 1.01 & \\
\hline \multirow{14}{*}{$\begin{array}{l}\text { Employees } \\
\text { Self-report }\end{array}$} & \multirow[t]{2}{*}{ Innovation } & Outstanding & $1.50-7.00$ & 5.53 & 1.12 & \multirow{2}{*}{1.33} \\
\hline & & Common & $1.90-7.00$ & 5.34 & 1.14 & \\
\hline & \multirow[t]{2}{*}{ Personal Initiative } & Outstanding & $4.29-7.00$ & 6.12 & 0.68 & \multirow{2}{*}{$4.34^{* *}$} \\
\hline & & Common & $4.29-7.00$ & 5.71 & 0.74 & \\
\hline & \multirow[t]{2}{*}{ Agreeableness } & Outstanding & $3.00-7.00$ & 4.81 & 0.85 & \multirow{2}{*}{0.15} \\
\hline & & Common & $2.00-7.00$ & 4.79 & 0.96 & \\
\hline & \multirow[t]{2}{*}{ Conscientiousness } & Outstanding & $1.00-7.00$ & 4.39 & 0.87 & \multirow{2}{*}{$2.02^{*}$} \\
\hline & & Common & $2.00-6.00$ & 4.17 & 0.69 & \\
\hline & \multirow[t]{2}{*}{ Emotional Stability } & Outstanding & $2.00-7.00$ & 4.29 & 0.85 & \multirow{2}{*}{$2.78^{\star *}$} \\
\hline & & Common & $1.50-6.00$ & 4.00 & 0.74 & \\
\hline & \multirow[t]{2}{*}{ Extraversion } & Outstanding & $2.00-7.00$ & 4.29 & 1.04 & \multirow{2}{*}{0.54} \\
\hline & & Common & $2.00-7.00$ & 4.23 & 0.86 & \\
\hline & \multirow[t]{2}{*}{ Openness to Experiences } & Outstanding & $3.50-7.00$ & 5.28 & 1.12 & \multirow{2}{*}{-1.73} \\
\hline & & Common & $3.00-7.00$ & 5.51 & 0.95 & \\
\hline
\end{tabular}

Note: Outstanding employees $n=189$, Common employees $n=182{ }^{*} P<0.05,{ }^{* *} P<0.01,{ }^{* \star *} P<0.001$

Table 2 summarizes the results of a regression analysis used to explain the effect of personality traits and Innovation on Performance. The results of the regression analysis indicate that approximately $32 \%$ of the variance in outstanding employee's performance is explained by personality traits and Innovation. On the one hand, supervisors evaluated their outstanding employees as highly innovative. On the other hand, outstanding employees did not rate themselves as highly innovative as common employees did. Among the FFM traits, outstanding employees with high levels of agreeableness are significant correlated with OCB-O, while those with high levels of extraversion are significant related to OCB-I. On the contrary, outstanding employees with high levels of openness to experience are negatively related to OCB-O and task performance. 
Table 2: Regression analysis personality traits and Innovation, and socio demographic variables as predictors of employees performance

\begin{tabular}{|c|c|c|c|c|c|c|}
\hline \multirow[b]{2}{*}{ Variables } & \multicolumn{2}{|c|}{ OCB_I } & \multicolumn{2}{|c|}{ OCB_O } & \multicolumn{2}{|c|}{ Task Performance } \\
\hline & Outstanding & Common & Outstanding & Common & Outstanding & Common \\
\hline Gender & -0.12 & -0.04 & 0.01 & $-0.15^{\star}$ & $-0.15^{\star}$ & $-0.23^{\star}$ \\
\hline Seniority & 0.06 & $-0.21^{\text {** }}$ & $0.13^{*}$ & 0.02 & 0.11 & $-0.16^{\star}$ \\
\hline Education & -0.03 & 0.05 & 0.05 & -0.10 & 0.07 & $0.19^{\star}$ \\
\hline Agreeableness & 0.12 & 0.01 & $0.19^{\star}$ & -0.02 & 0.10 & -0.06 \\
\hline Conscientiousness & -0.13 & 0.08 & 0.04 & 0.04 & 0.01 & -0.07 \\
\hline $\begin{array}{l}\text { Emotional Stability } \\
\text { Extraversion }\end{array}$ & $\begin{array}{l}-0.01 \\
\mathbf{0 . 1 7}\end{array}$ & $\begin{array}{l}0.02 \\
0.04\end{array}$ & $\begin{array}{c}0.92 \\
-0.14\end{array}$ & $\begin{array}{l}-0.12 \\
-0.07\end{array}$ & $\begin{array}{l}0.06 \\
0.00\end{array}$ & $\begin{array}{l}-0.10 \\
-0.05\end{array}$ \\
\hline $\begin{array}{l}\text { Openness to } \\
\text { Experiences }\end{array}$ & -0.10 & 0.14 & $-0.21^{\star \star}$ & -0.05 & $-0.16^{\star}$ & -0.16 \\
\hline Personal Initiative & -0.02 & 0.14 & 0.00 & 0.05 & 0.03 & 0.06 \\
\hline $\begin{array}{l}\text { Innovation by } \\
\text { Employees }\end{array}$ & -0.03 & 0.03 & 0.15 & 0.10 & 0.06 & $0.26^{\star \star}$ \\
\hline $\begin{array}{l}\text { Innovation by } \\
\text { Supervisors }\end{array}$ & $0.56^{\star \star \star}$ & $0.29^{\star \star \star}$ & $0.54^{\star \star \star}$ & $0.38^{\star \star \star}$ & $0.51^{\star \star \star}$ & $0.13^{\star}$ \\
\hline $\mathrm{R}^{2}$ & $32 \%$ & $24.1 \%$ & $38.7 \%$ & $23.2 \%$ & $31.8 \%$ & $22.7 \%$ \\
\hline Adjusted $\mathrm{R}^{2}$ & $27.2 \%$ & $15.3 \%$ & $34.4 \%$ & $17 \%$ & $27 \%$ & $16.8 \%$ \\
\hline $\mathrm{F}$ & $6.68^{* \star *}$ & $2.74^{* *}$ & $8.95^{\star \star *}$ & $3.97^{* * *}$ & $6.62^{* \star *}$ & $3.86^{\star *}$ \\
\hline
\end{tabular}

Note: Outstanding employees $n=189$, Common employees $n=182{ }^{*} P<0.05,{ }^{* *} P<0.01,{ }^{* \star *} P<0.001$

\section{Discussion}

This study enriches the literature on knowledge management and entrepreneurship behavior. It explores the phenomenon of innovative work behavior in outstanding employees and compares it to common performance employees. The aim has been to understand in depth the relationship comprising personality traits, outstanding performance, and innovation within organization settings. Understanding the metadata underlying personnel's entrepreneur behavior, their creation and sharing of knowledge, may help HRMs to better manage knowledge on their employees, including its creation and performance processes. This ought to qualitatively transform collected data into professionally useful knowledge [8], and allow employees to significantly improve their company's performance [9]. In other words, collecting knowledge about their innovatively performing employees, may allow organizations to generate new operational knowledge, which this may manage and further apply in product innovation and entrepreneurship. For this purpose, we have simultaneously measured employees' self-reports on personality and innovation, along with their supervisors' ratings of their performance and innovative behavior.

Our findings reveal that there is a positive connection between subordinate innovative behavior and supervisor performance assessment, both concerning outstanding performers and concerning common employees. Moreover, this study analyzes the relationship comprising personality traits, innovative work behavior, and outstanding employee's performance. It enlightens the relationship between task and contextual performance, understood as OCB-I and OCB-O as a mechanism whereby different contextual activities shape those organizational activities [81] that lead to innovation and entrepreneurship [82]. In this context, we show that supervisor's ratings of contextual behaviors have a positive impact on performance evaluations [83, 84].

More specifically, this paper reveals that outstanding employees scoring high on agreeableness are significantly correlated with OCB-O, while those showing high levels of extraversion are significantly 
correlated with OCB-I. Both findings may be traced back to the FFM's characterology. In this regard, one may argue that agreeableness' strong connection to OCB-O is based on this trait's predominantly prosocial behaviors [49], among which one may count compliant, sympathetic, trusting, adapting, and cooperative inclinations [48]. As to extroverts' high correlation with OCB-I, this may be a result of these individuals' propensity to welcome challenges and changes [53], and stand out through innovation [57], all of which may reveal a sound individualistic personality, self-reliance, and assertiveness.

On the other hand, our findings reveal that outstanding employees scoring high on openness to experience are negatively correlated with both OCB-O and task performance. In line with the FFM characterology, one may argue, this is due to these individual's flexibility, curiosity, and imaginative character [45], which is augmented by their constant need to pursuit novelty in new environments and search for new experiences [55]. The reason for this may be that individuals possessing the open to experience trait tend to be inhibited by conventional tasks, score lower on self-assessment, are less structured, and seldom tend to follow routines, as for instance, working full-time as it is usually required in the public administration [85].

Accordingly, the paper's contribution to the research literature is: First, we analyze the relationship among personality traits, innovation, and task and contextual performance, i.e., OCB. Thereby, we provide a new theoretical tool for Human Resources Management's units to acquire knowledge about their employees. This tool may be used to identify entrepreneurial behavior. More specifically, by employing our tool HMR's units may be able to understand how employees' innovative knowledge processes and personality traits apply when interacting with their supervisors' assessments. In other words, apart from enriching the scientific literature in the field of knowledge management, the above tool can assist HRMs undertake those actions necessary for organizational improvement leading to the development of human capital and competitiveness. Secondly, we analyze the processes leading to outstanding performance and innovation in organizations, both at its task and contextual performance's levels as assessed by self-reports and supervisors' ratings, which contributes to increasing profitability via effective knowledge management.

In line with the scientific literature [29], this research's findings may help management units understand the knowledge underlying employees' innovative behavior. The fruitful management thereof could assist them in adopting new organizational strategies and incentive policies to promote entrepreneurial behavior.

To sum up, the processes involving outstanding employees and entrepreneurship behaviors lead to product and service innovation. This allows organizational development and helps secure competitiveness levels at the global market. In addition, the foregoing creates organizational information or knowledge as to HOW the above processes take place, which may be stored, managed and shared in future situations to increase and improve organizational productivity. Such knowledge may be applied when further innovation is required. Creating new organizational data on outstanding employees' performance and innovation processes could be subsequently used for new inventions.

\section{Limitations and Future Research}

Despite its practical and theoretical contributions, this research has limitations which could be addressed by future research. First, it presupposes the generalizable validity of personality measurements of job performance as manifested in the Israeli public sector, as any other inductive model reflecting on particular data does. This also true of Hofstede's wellknown cultural dimensions approach, to which one may prima facie point to as a candidate to add certainty to the above generalization. Accordingly, the Big Five Model, on which this study relies, maybe still seen as a universally agreed personality trait model, applicable to everyone, everywhere, disregarding cultural backgrounds. Nonetheless, it would be recommendable to perform an additional research centering on the influence of specific cultural backgrounds on personality traits. Second, the individual determinants of performance may not be innovative per se, however, the overall system of determinants has significant implications. Like any other empirical researches, ours is a specific theoretical construct analyzing and reflecting a given practice (its data). In other words, our model offers a particularized, theoretical perspective of a general, socio-cultural phenomenon. This entails that research, theory, and practice could all benefit from similar tests focusing on additional contexts and employing different predictors.

\section{References}

[1] Issahaka, A.W., and R. Lines, "Knowledge workers: How are they different?(and why does it matter?)", Journal of Organizational Psychology 19(5), 2019.

[2] Kerr, W.R., "The gift of global talent: Innovation policy and the economy", Innovation Policy and the Economy 20(1), 2020, pp. 1-37. 
[3] Gloet, M., and D. Samson, "Knowledge management and systematic innovation capability", In Disruptive Technology: Concepts, Methodologies, Tools, and Applications. IGI Global, 2020, 1198-1218.

[4] Gloet, M., and D. Samson, "Creating value through knowledge management and systematic innovation capability", In Knowledge Management, Innovation, and Entrepreneurship in a Changing World. IGI Global, Pennsylvania, 2020, 1-30.

[5] Aldahdouh, T.Z., V. Korhonen, and P. Nokelainen, "What contributes to individual innovativeness? A multilevel perspective", International Journal of Innovation Studies 3(2), 2019, pp. 23-39.

[6] Jennex, M., S. Smolnik, and D. Croasdell, "Knowledge Value, Success, and Performance Measurements", Proceedings of the 52nd Hawaii International Conference on System Sciences, (2019).

[7] Alonso-Gonzalez, A., M. Peris-Ortiz, and J.J. Cao-Alvira, "Personal branding as a knowledge management tool to enhance innovation and sustainable development in organizations", In M. Peris-Ortiz, J.J. Ferreira and J.M. Merigó Lindahl, eds., Knowledge, innovation and sustainable development in organizations: A dynamic capabilities perspective. Springer, Cham, 2019, 113-129.

[8] Schniederjans, D.G., C. Curado, and M. Khalajhedayati, "Supply chain digitisation trends: An integration of knowledge management", International Journal of Production Economics 220, 2020, pp. 107439.

[9] Shujahat, M., M.J. Sousa, S. Hussain, F. Nawaz, M. Wang, and M. Umer, "Translating the impact of knowledge management processes into knowledge-based innovation: The neglected and mediating role of knowledge-worker productivity", Journal of Business Research 94, 2019, pp. 442-450.

[10] Sherringham, K., and B. Unhelkar, "Knowledge workers and rapid changes in technology", In K. Sherringham and B. Unhelkar, eds., Crafting and Shaping Knowledge Worker Services in the Information Economy. Springer Singapore, Singapore, 2020, 1-48.

[11] Linda, M., and M.A. Foster, "Innovative work behavior through high-quality leadership", International Journal of Innovation Science 12(2), 2020, pp. 219-236.

[12] Jasińska-Biliczak, A., J. Kowal, and J. Hafner, "Innovative capacity in small regional enterprises in transition economies: An exploratory study in Poland", Proceedings of the Twenty-second Americas Conference on Information Systems (AMCIS), San Diego, California, USA, (2016), 11-14. [13] Ioannis, R., and D. Belias, "Combining strategic management with knowledge management: Trends and international perspectives", International Review of Management and Marketing 10(3), 2020, pp. 39-45.

[14] Vukšić, V.B., M.P. Bach, H.T. Inkinen, A. Kianto, and M. Vanhala, "Knowledge management practices and innovation performance in Finland", Baltic Journal of Management, 2015.

[15] Antunes, H. de J.G., and P.G. Pinheiro, "Linking knowledge management, organizational learning and memory", Journal of Innovation and Knowledge 5(2), 2020, pp. 140-149.

[16] Kalashi, M., V. Bakhshalipour, B. Azizi, and S.K.
Sareshkeh, "The effect of the application of ICT skills on the process of knowledge management components and the effectiveness of creativity of creativity indicators for the improvement of employees' performance system in the Ministry of Sports and Youth", World Journal on Educational Technology: Current Issues 12(1), 2020, pp. 48-62.

[17] Law, J., "knowledge management", 2016.

[18] Valdez-Juárez, L.E., D. García-Pérez de Lema, and G. Maldonado-Guzmán, "Management of knowledge, innovation and performance in SMEs", Interdisciplinary Journal of Information, Knowledge, and Management 11, 2016, pp. 141176.

[19] Cabrilo, S., and S. Dahms, "How strategic knowledge management drives intellectual capital to superior innovation and market performance", Journal of Knowledge Management 22(3), 2018, pp. 621-648.

[20] Neto, J.C., J.A. Filipe, and A.B. Caleiro, "Creativity and innovation: A contribution of behavioral economics", International Journal of Innovation Studies 3(1), 2019, pp. $12-21$.

[21] Theurer, C.P., A. Tumasjan, and I.M. Welpe, "Contextual work design and employee innovative work behavior: When does autonomy matter?", PloS one 13(10), 2018, pp. e0204089.

[22] Schuh, S.C., X. Zhang, F.P. Morgeson, P. Tian, and R. van Dick, "Are you really doing good things in your boss's eyes? Interactive effects of employee innovative work behavior and leader-member exchange on supervisory performance ratings", Human Resource Management 57(1), 2018, pp. 397-409.

[23] Ghitulescu, B.E., "Psychosocial effects of proactivity: The interplay between proactive and collaborative behavior", Personnel Review 47(2), 2018, pp. 294-318.

[24] Dimitriadis, E., T. Anastasiades, D. Karagiannidou, and M. Lagaki, "Creativity and entrepreneurship: The role of gender and personality", International Journal of Business and Economic Sciences Applied Research (IJBESAR) 11(1), 2017, pp. 7-12.

[25] Razzaq, S., M. Shujahat, S. Hussain, et al., "Knowledge management, organizational commitment and knowledgeworker performance: The neglected role of knowledge management in the public sector", Business Process Management Journal 25(5), 2018, pp. 923-947.

[26] Van Laethem, M., D.G.J. Beckers, J. de Bloom, M. Sianoja, and U. Kinnunen, "Challenge and hindrance demands in relation to self-reported job performance and the role of restoration, sleep quality, and affective rumination", Journal of Occupational and Organizational Psychology 92(2), 2019, pp. 225-254.

[27] Xiaojun, Z., "Knowledge Management System use and job performance: A multilevel contingency model", MIS quarterly 41(3), 2017.

[28] Abner, G.B., S.Y. Kim, and J.L. Perry, "Building evidence for public human resource management: Using middle range theory to link theory and data", Review of Public Personnel Administration 37(2), 2017, pp. 139-159.

[29] Diamantidis, A.D., and P. Chatzoglou, "Factors affecting employee performance: an empirical approach", International Journal of Productivity and Performance Management 68(1), 2019, pp. 171-193. 
[30] Motowidlo, S.J., W.C. Borman, and M.J. Schmit, "A theory of individual differences in task and contextual performance", Human Performance 10(2), 1997, pp. 71-83.

[31] Borman, W.C., and S.J. Motowidlo, "Task performance and contextual performance: The meaning for personnel selection research", Human performance 10(2), 1997, pp. 99 109.

[32] Christian, M.S., A.S. Garza, and J.E. Slaughter, "Work engagement: A quantitative review and test of its relations with task and contextual performance", Personnel Psychology 64(1), 2011, pp. 89-136.

[33] Motowidlo, S.J., and J.R. Van Scotter, "Evidence that task performance should be distinguished from contextual performance", Journal of Applied Psychology 79(4), 1994, pp. 475-480.

[34] Fletcher, C., "Performance appraisal and management: The developing research agenda", Journal of Occupational and Organizational Psychology 74(4), 2001, pp. 473-487.

[35] Mathisen, G.E., Ø. Martinsen, and S. Einarsen, "The relationship between creative personality composition, innovative team climate, and team innovativeness: An inputprocess-output perspective", The Journal of Creative Behavior 42(1), 2008, pp. 13-31.

[36] Stone-Romero, E.F., K. Alvarez, and L.F. Thompson, "The construct validity of conceptual and operational definitions of contextual performance and related constructs", Human Resource Management Review 19(2), 2009, pp. 104116.

[37] Tufail, M.S., H.A. Mahesar, and S.K. Pathan, "Organizational justice, task and contextual performance: Empirical analysis for front line managers", Grassroots 51(1), 2017.

[38] Cetinkaya, A.S., and M. Rashid, "The effect of social media on employees' job performance: The mediating role of organizational structure", Journal of Organizational Psychology, 18(4), 2018, pp. 1-21.

[39] Spitzmuller, M., R. Ilies, and D. Choi, "Organizational Citizenship Behaviors: A new look at an old phenomenon at differentlevels", In D.O. Ones, N. Anderson, C. Viswesvaran and H.K. Sinangil, eds., The SAGE handbook of industrial, work and organizational psychology: Personnel psychology and employee performance. SAGE, Los Angeles, 2018, 89-.

[40] Eshet, Y., "Outstanding employees: Antecedents of employees' outstanding performance in organizations”, 2017. [41] Elliot, A.J., "A conceptual history of the achievement goal construct”, In A.J. Elliot and C.S. Dweck, eds., Handbook of Competence and Motivation. The Guilford Press, New York, 2005, 52-72.

[42] van Loon, N., A.M. Kjeldsen, L.B. Andersen, W. Vandenabeele, and P. Leisink, "Only when the societal impact potential is high? A panel study of the relationship between public service motivation and perceived performance", Review of public personnel administration 38(2), 2018, pp. 139-166.

[43] Eshet, Y., "Innovation in outstanding performance", 36th EGOS Colloquium, (2020), 1-22.

[44] Hung, W.-T., "Revisiting relationships between personality and job performance: Working hard and working smart", Total Quality Management \& Business Excellence 31(7-8), 2020, pp. 907-927.
[45] Woods, S.A., M.J. Mustafa, N. Anderson, and B. Sayer, "Innovative work behavior and personality traits: Examining the moderating effects of organizational tenure", Journal of Managerial Psychology 33(1), 2018, pp. 29-42.

[46] Yesil, S., and F. Sozbilir, "An empirical investigation into the impact of personality on individual innovation behaviour in the workplace", Procedia-Social and Behavioral Sciences 81, 2013, pp. 540-551.

[47] Watson, D., E. Nus, and K.D. Wu, "Development and validation of the Faceted Inventory of the Five-Factor Model (FI-FFM)", Assessment 26(1), 2019, pp. 17-44.

[48] Huang, J.L., A.M. Ryan, K.L. Zabel, and A. Palmer, "Personality and adaptive performance at work: A metaanalytic investigation", Journal of Applied Psychology 99(1), 2014, pp. 162-179.

[49] Hamidullah, M.F., G.G. van Ryzin, and H. Li, "The agreeable bureaucrat: Personality and PSM", International Journal of Public Sector Management 29(6), 2016, pp. 582595.

[50] Monzani, L., P. Ripoll, and J.M. Peiró, "The moderator role of followers' personality traits in the relations between leadership styles, two types of task performance and work result satisfaction", European Journal of Work and Organizational Psychology 24(3), 2015, pp. 444-461.

[51] Hamdy, A., K. Fazida, M.I. Rashidah, et al., "Connecting the dots between the Big Five and innovative work behaviour: Maslow and Maqasid Al-Shari'a Perspectives", Revista ESPACIOS 40(27), 2019, pp. 1-12.

[52] Qaiser Danish, R., A. Asghar, M.J. e Kausar, et al., "Impact of personality characteristics on innovative work behavior through emotional labor in Education Sector of Pakistan", European Online Journal of Natural and Social Sciences: Proceedings 8(2), 2019, pp. 70-85.

[53] Frieder, R.E., G. Wang, and I.-S. Oh, "Linking jobrelevant personality traits, transformational leadership, and job performance via perceived meaningfulness at work", Journal of Applied Psychology 103(3), 2017, pp. 324-333.

[54] Chiaburu, D.S., I.S. Oh, C.M. Berry, N. Li, and R.G. Gardner, "The five-factor model of personality traits and organizational citizenship behaviors: A meta-analysis", Journal of Applied Psychology 96(6), 2011, pp. 1140-1166.

[55] Costa, P.T., and R.R. McCrae, "Neo Personality Inventory-Revised (NEO PI-R)", In Psychological Assessment Resources. 1992.

[56] Barrick, M.R., and M.K. Mount, "The Big Five Personality Dimensions and job performance: A metaanalysis.”, Personnel Psychology 44(1), 1991, pp. 1-26.

[57] Luo, Y., Z. Cao, L. Yin, H. Zhang, and Z. Wang, "Relationship between extraversion and employees' innovative behavior and moderating effect of organizational innovative climate", NeuroQuantology 16(6), 2018, pp. 186194.

[58] Wihler, A., G. Blickle, B.P. Ellen, W.A. Hochwarter, and G.R. Ferris, "Personal initiative and job performance evaluations: Role of political skill in opportunity recognition and capitalization", Journal of Management 43(5), 2017, pp. 1388-1420.

[59] Johnson, L.U., A. Rogers, R. Stewart, E.M. David, and L.A. Witt, "Effects of politics, emotional stability, and LMX on job dedication", Journal of Leadership and Organizational 
Studies 24(1), 2017, pp. 121-130.

[60] Barrick, M.R., M.K. Mount, and R. Gupta, "Metaanalysis of the relationship between the Five-Factor Model of personality and Holland's occupational types", Personnel psychology 56(1), 2003, pp. 45-74.

[61] Judge, T.A., and A. Erez, "Interaction and intersection: The constellation of emotional stability and extraversion in predicting performance", Personnel Psychology 60(3), 2007, pp. 573-596.

[62] Abdullah, I., R. Omar, and S.A. Panatik, "A literature review on personality, creativity and innovative behavior", International Review of Management and Marketing 6(1), 2016, pp. 177-182.

[63] Zare, M., and C. Flinchbaugh, "Voice, creativity, and big five personality traits: A meta-analysis", Human Performance 32(1), 2019, pp. 30-51.

[64] Hsieh, H.-L., J.-R. Hsieh, and I.-L. Wang, "Linking personality and innovation: The role of knowledge management", World Transactions on Engineering and Technology Education 9(1), 2011, pp. 38-44.

[65] Ali, I., "Personality traits, individual innovativeness and satisfaction with life", Journal of Innovation and Knowledge 4(1), 2019, pp. 38-46.

[66] Furnham, A., D.J. Hughes, and E. Marshall, "Creativity, OCD, narcissism and the Big Five", Thinking Skills and Creativity 10, 2013, pp. 91-98.

[67] McCrae, R.R., and P.T. Costa, "Validation of the FiveFactor Model of personality across instruments and observers", Journal of Personality and Social Psychology 52(1), 1987, pp. 81-90.

[68] Feist, G.J., "A meta-analysis of personality in scientific and artistic creativity", Personality and social psychology review 2(4), 1998, pp. 290-309.

[69] Furnham, A., and M. Nederstrom, "Ability, demographic and personality predictors of creativity", Personality and individual differences 48(8), 2010, pp. 957-961.

[70] Mumford, M.D., and M.E. Todd, "Creativity and innovation at work", In M.D. Mumford and M.E. Todd, eds., Creativity and Innovation in Organizations. Routledge, New York, 2020, 1-15.

[71] Åmo, B.W., and L. Kolvereid, "Organizational strategy, individual personality and innovation behavior", Journal of Enterprising Culture 13(01), 2005, pp. 7-19.

[72] Newman, A., H.M. Herman, G. Schwarz, and I. Nielsen, "The effects of employees' creative self-efficacy on innovative behavior: The role of entrepreneurial leadership", Journal of Business Research 89, 2018, pp. 1-9.
[73] Frese, M., and D. Fay, "Personal initiative: An active performance concept for work in the 21 st century", RIOB Research in Organizational Behavior 23, 2001, pp. 133-187. [74] Grant, A.M., S. Parker, and C. Collins, "Getting credit for proactive behavior: Supervisor reactions depend on what you value and how you feel", Personnel Psychology 62(1), 2009, pp. 31-55.

[75] Bolino, M., S. Valcea, and J. Harvey, "Employee, manage thyself: The potentially negative implications of expecting employees to behave proactively", Journal of Occupational and Organizational Psychology 83(2), 2010, pp. 325-345.

[76] Scott, S.G., and R.A. Bruce, "Determinants of innovative behavior: A path model of individual innovation in the workplace", Academy of management journal 37(3), 1994, pp. 580-607.

[77] Gosling, S.D., P.J. Rentfrow, and W.B. Swann, "A very brief measure of the Big-Five personality domains", Journal of Research in Personality 37(6), 2003, pp. 504-528.

[78] Williams, L.J., and S.E. Anderson, "Job satisfaction and organizational commitment as predictors of organizational citizenship and in- role behaviors", Journal of Management 17(3), 1991, pp. 601-617.

[79] Moorman, R.H., and G.L. Blakely, "Individualismcollectivism as an individual difference predictor of organizational citizenship behavior", Journal of Organizational Behavior 16(2), 1995, pp. 127-142.

[80] Jawahar, I.M., and G.R. Ferris, "A longitudinal investigation of task and contextual performance influences on promotability judgments", Human Performance 24(3), 2011, pp. 251-269.

[81] Cepiku, D., A. Hinna, D. Scarozza, and A.B. Savignon, "Performance information use in public administration: an exploratory study of determinants and effects", Journal of Management \& Governance 21(4), 2017, pp. 963-991.

[82] Yasir, M., M. Adil, M.N. Khan, M.S. Malik, and F. Khan, "Outcomes of personal social media usage in the workplace", Journal of Managerial Sciences 11(3), 2017, pp. 547-558.

[83] Moura, A.O.R., and L.C. Oliveira-Silva, "Work centrality, goals and professional fulfillment: intersections between work and career", Revista de Administração Mackenzie 20(1), 2019.

[84] Ones, D., N. Anderson, C. Viswesvaran, and H. Sinangil, The Sage handbook of industrial, work and organizational psychology: Personnel psychology and employee performance, SAGE, Thousand Oaks, 2018.

[85] Eshet, Y., "Personality Traits' predictors of outstanding performance in the Public Sector", Under-review, 2020. 